\title{
Ordered Array Formation and Negative Differential Resistance Behavior of Cation-Exchanged Heteropoly Acids Probed by Scanning Tunneling Microscopy
}

\author{
Mahmoud S. Kaba, In K. Song, ${ }^{\dagger}$ and Mark A. Barteau* \\ Center for Catalytic Science and Technology, Department of Chemical Engineering, University of Delaware, \\ Newark, Delaware 19716
}

Received: July 23, 1996; In Final Form: October 4, $1996^{\otimes}$

\begin{abstract}
Cation-exchanged 12-molybdophosphates deposited on a graphite surface were imaged by scanning tunneling microscopy (STM), and their current-voltage behavior in tunneling spectroscopy (TS) measurements was examined. The periodicity of the polyanion arrays in the STM images was ca. 11-14 A, and the spacing was dependent on the identity of the countercation. It was also observed that the characteristic negative differential resistance (NDR) behavior of 12-molybdophosphates, observed in TS measurements, is closely related to the reduction potential of the polyoxometalate and to the electronegativity of the countercation. The applied potential (sample to tip) at which NDR behavior was observed decreased with increases in the reduction potential of the HPA as well as with increases in electronegativity of the countercation. More electronegative countercations facilitated electron transfer between the cation and the heteropoly anion, apparently by acting as electron reservoirs, leading to NDR behavior at lower applied voltages and generating higher reduction potentials. This work demonstrates the first correlation between tunneling spectra measured by STM and the chemical properties of polyoxometalates.
\end{abstract}

\section{Introduction}

Heteropoly acids (HPAs) such as $\mathrm{H}_{3} \mathrm{PMo}_{12} \mathrm{O}_{40}$ are inorganic acids but at the same time can act as oxidizing agents. ${ }^{1-3}$ Many are highly soluble in polar solvents such as water, alcohols, and amines but insoluble in some nonpolar solvents such as benzene and olefins. ${ }^{4,5}$ The solubility of these compounds in turn is closely connected to their ability to adsorb various reactants. Nonpolar molecules are adsorbed on the surface of bulk HPAs, while most polar molecules are mainly absorbed in the bulk, forming what Misono has described as a "pseudoliquid" phase. ${ }^{6}$ This characteristic leads to two typical catalytic reaction types involving HPAs: surface-type and bulk-type reactions. It is well-known that the acid and redox properties of HPAs can be modified by substituting the protons with certain metal cations. ${ }^{7}$ The size of the Keggin-type heteropoly anion, the so-called primary structure, is ca. $10-12 \AA$ as determined in previous works by $\mathrm{X}$-ray crystallography ${ }^{8,9}$ and scanning tunneling microscopy. ${ }^{10}$

STM can provide real space images of catalyst surfaces with angstrom scale resolution. ${ }^{11}$ Insulating materials have been imaged using STM by depositing thin films on a conducting substrate such as graphite, ${ }^{12}$ and several models ${ }^{13,14}$ have been proposed to explain the significant tunneling current measured in these systems. STM images for several heteropoly and isopoly acids deposited on conductive substrates have been reported by various researchers. ${ }^{10,15-20}$ In tunneling spectroscopy experiments, we have consistently observed that HPAs deposited on graphite exhibit distinctive current-voltage (I$V)$ behavior, referred to as negative differential resistance (NDR). ${ }^{10,18-20}$

In this work, several water-soluble and water-insoluble cationexchanged 12-molybdophosphates were prepared and deposited on a highly oriented pyrolytic graphite (HOPG) surface to obtain

* To whom correspondence should be addressed. Tel 302-831-8056, Fax 302-831-2085, E-mail barteau@che.udel.edu.

Present address: Department of Industrial Chemistry, Kangnung National University, Kangnung, Kangwondo 210-702, Korea.

${ }^{\otimes}$ Abstract published in Advance ACS Abstracts, November 15, 1996. images and tunneling spectra by STM. These data serve to establish a correlation between NDR behavior in the tunneling spectrum of the HPA monolayer and its reduction potential, i.e., the oxidizing power of the heteropoly acid catalyst. This is the first example of such a correlation using STM.

\section{Experimental Section}

HPA Preparation and Deposition. $\mathrm{H}_{3} \mathrm{PMo}_{12} \mathrm{O}_{40}$ was obtained from Aldrich Chemical Co. It was dissolved in water and recrystallized by slow heating at $100{ }^{\circ} \mathrm{C}$. It was then calcined at $300{ }^{\circ} \mathrm{C}$ for $2 \mathrm{~h}$ to remove water of crystallization. $\mathrm{H}_{3-x} \mathrm{Cs}_{x} \mathrm{PMo}_{12} \mathrm{O}_{40}(x=0,1,2,3), \mathrm{H}_{3-x} \mathrm{Cu}_{x / 2} \mathrm{PMo}_{12} \mathrm{O}_{40}(x=0$, 1, 2, 3), $\mathrm{K}_{3} \mathrm{PMo}_{12} \mathrm{O}_{40}, \mathrm{Mg}_{3 / 2} \mathrm{PMo}_{12} \mathrm{O}_{40}$, and $\mathrm{BiPMo}_{12} \mathrm{O}_{40}$ were then prepared by ion exchange using procedures described elsewhere. ${ }^{21,22}$ Approximately 0.01 $\mathrm{M}$ aqueous solutions of each sample were prepared. A drop of solution was deposited on freshly cleaved HOPG and allowed to dry in air for ca. 45 min at room temperature. For the nominally water-insoluble cesium and potassium salts, the vial was vigorously shaken before a drop of the very fine suspended particles in solution was deposited on the graphite surface to dry in air. It is possible that, in each ion-exchange reaction to produce a specific sample, there may have been other products of varying cation content; however, for each of these samples deposited on graphite, subsequent imaging of several different sites on the adsorbed HPA surface by STM showed ordered arrays of polyanions that had consistent periodicities, and tunneling spectroscopy (TS) measurements on these anions yielded negative differential resistance (NDR) behavior ${ }^{10}$ at consistent values of the applied potential. HPAs are known to exhibit NDR behavior in their tunneling spectra, and the potential at which this behavior is observed can be used as a fingerprint of the HPA. ${ }^{10}$ Both the array spacing ${ }^{18}$ and NDR peak voltage were found to vary for samples in which the proton content was deliberately varied by ion exchange, e.g., for the series $\mathrm{H}_{3-x} \mathrm{Cs}_{x} \mathrm{PMo}_{12} \mathrm{O}_{40}$. The absence of such variations among different regions of the same sample probed by STM and TS suggests that the composition of the surface HPA arrays is spatially uniform. In agreement 


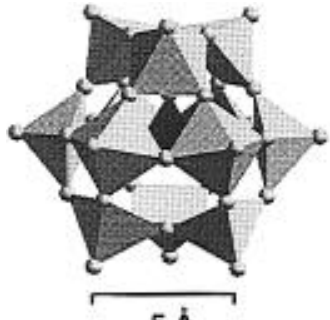

$5 \AA$

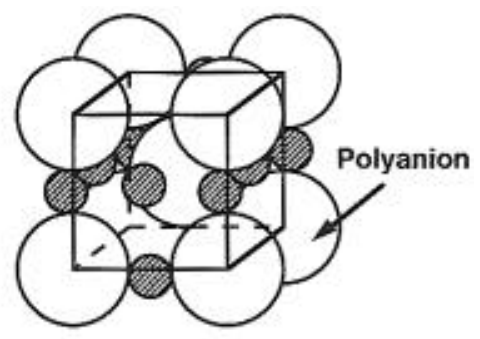

Primary structure $=\mathrm{H}^{+}\left(\mathrm{H}_{2} \mathrm{O}\right)_{n}, \mathrm{Cs}^{+}, \mathrm{Cu}^{2+}, \mathrm{K}^{+}, \mathrm{Mg}^{2+}$, etc.

\section{Secondary structure ${ }^{25}$}

Figure 1. A polyhedral representation of the Keggin anion (primary structure) and a schematic of the secondary structure ${ }^{25}$ of heteropoly acids showing bridging cations, protons, water of crystallization, etc.

with other STM reports, ${ }^{10,18}$ the TS measurements also indicated that the HPAs formed monolayers on the graphite surfaces, as the tunneling spectrum of graphite was obtained at high symmetry interstitial sites in these arrays.

STM and Tunneling Spectroscopy. STM images were obtained in air using a Topometrix TMX 2010 instrument. Mechanically formed Pt/Ir tips were used. Scanning was done in the constant current mode at a positive sample bias of 100 $\mathrm{mV}$ and tunneling current of $1-2 \mathrm{nA}$. Tunneling spectra were measured in air and in a glovebox filled with $\mathrm{N}_{2}$. Both Topometrix TMX 2010 and LK Technologies LK-1000 STM instruments were used to perform these measurements and to demonstrate consistency and reproducibility. All STM images presented in this report are unfiltered, and the reported periodicities are average values determined by performing fast Fourier transform analyses on at least three images for each sample. Each image was acquired using a different tip; the tips were first calibrated by imaging bare HOPG. Several tunneling spectroscopy measurements were then performed on the bare graphite section of the surface to ensure the stability of the tip and the reproducibility of the tunneling spectrum of HOPG. Once these had been established, the "good" tip would be moved to the HPA-covered section to image and obtain tunneling spectra of the HPA sample. To measure a tunneling spectrum, the sample bias was ramped from -2 to $+2 \mathrm{~V}$ with respect to the tip, and the tunneling current was monitored. The voltage axis in the tunneling spectrum represents the potential applied to the sample relative to that of the tip.

\section{Results and Discussion}

Ordered Arrays of Cation-Exchanged 12-Molybdophosphates. The primary structure of the heteropoly anion is very stable and is not changed by its surroundings. The threedimensional structure of the solid state comprising heteropoly anions, protons, cations, water, and organics is called the secondary structure. ${ }^{23}$ Figure 1 shows a polyhedral representation of the primary structure and a schematic of the secondary structure of heteropoly acids. Unlike the primary structure, the secondary structure is very labile and is likely to change in different surroundings by either increasing or decreasing the lattice spacing between the polyanions. Figure 2 shows STM images of $\mathrm{H}_{3} \mathrm{PMo}_{12} \mathrm{O}_{40}, \mathrm{Cu}_{3 / 2} \mathrm{PMo}_{12} \mathrm{O}_{40}$, and $\mathrm{Cs}_{3} \mathrm{PMo}_{12} \mathrm{O}_{40}$ deposited on HOPG. Images of HOPG with periodicities of ca. $2.5 \AA$ and exhibiting its characteristic tunneling spectrum ${ }^{10}$ were also obtained prior to acquiring the STM images of the HPAs. This was the standard calibration procedure to test the tips in our STM measurements. The STM image of $\mathrm{H}_{3^{-}}$ $\mathrm{PMo}_{12} \mathrm{O}_{40}$ deposited on HOPG is shown in Figure 2a and clearly indicates the formation of an ordered structure on the surface.

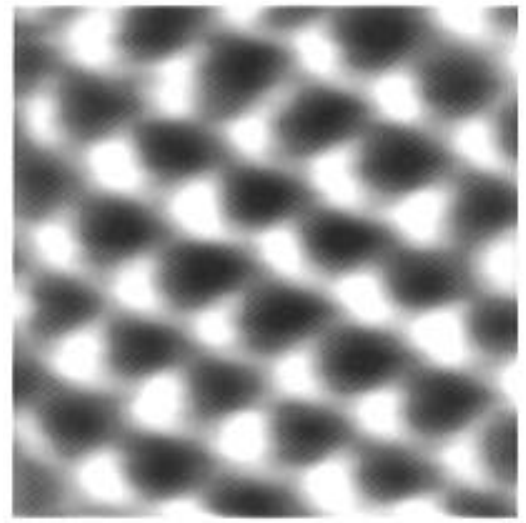

\section{$5.07 \mathrm{~nm} \times 5.07 \mathrm{~nm}$}

$$
\mathrm{H}_{3} \mathrm{PMo}_{12} \mathrm{O}_{40}
$$

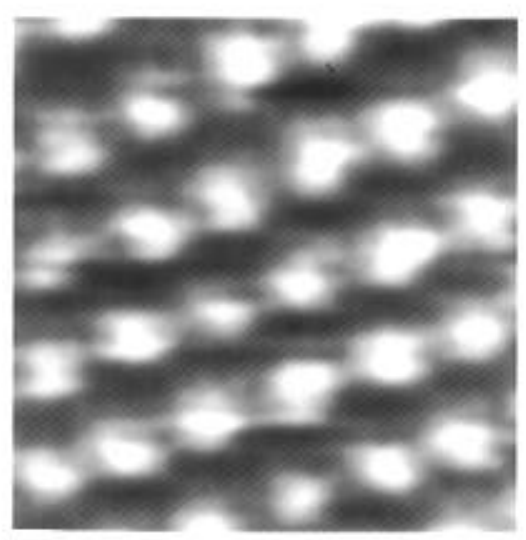

$6.45 \mathrm{~nm} \times 6.45 \mathrm{~nm}$

$$
\mathrm{Cu}_{3 / 2} \mathrm{PMO}_{12} \mathrm{O}_{40}
$$

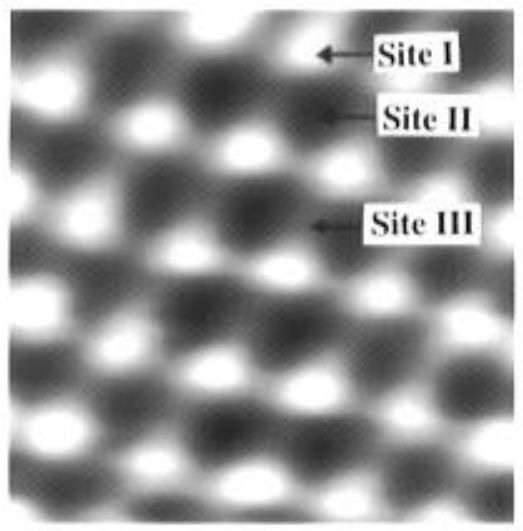

$7.0 \mathrm{~nm} \times 7.0 \mathrm{~nm}$

$$
\mathrm{Cs}_{3} \mathrm{PMo}_{12} \mathrm{O}_{40}
$$

Figure 2. STM images of (a) $\mathrm{H}_{3} \mathrm{PMo}_{12} \mathrm{O}_{40}$, (b) $\mathrm{Cu}_{3 / 2} \mathrm{PMo}_{12} \mathrm{O}_{40}$, and (c) $\mathrm{Cs}_{3} \mathrm{PMo}_{12} \mathrm{O}_{40}$.

Its periodicities are $10.77 \times 10.77 \pm 0.26 \AA$ and are in good agreement with values reported by $\mathrm{STM}^{10}$ and X-ray crystallography. 8,9 Parts $b$ and $c$ of Figure 2 show STM images of $\mathrm{Cu}_{3 / 2} \mathrm{PMo}_{12} \mathrm{O}_{40}$ and $\mathrm{Cs}_{3} \mathrm{PMo}_{12} \mathrm{O}_{40}$, respectively. The periodicities of $\mathrm{Cu}_{3 / 2} \mathrm{PMo}_{12} \mathrm{O}_{40}$ are $11.91 \times 11.91 \pm 0.22 \AA$, whereas those of $\mathrm{Cs}_{3} \mathrm{PMo}_{12} \mathrm{O}_{40}$ are $13.68 \times 13.68 \pm 0.14 \AA$. There is a significant difference in the periodicities of the typical watersoluble and water-insoluble phosphomolybdates. $\mathrm{Cu}_{3 / 2} \mathrm{PMo}_{12} \mathrm{O}_{40}$ is soluble in water, and $\mathrm{Cu}^{2+}$ has an ionic radius of $0.72 \AA .^{24}$ However, $\mathrm{Cs}_{3} \mathrm{PMo}_{12} \mathrm{O}_{40}$ is an insoluble compound with the countercation, $\mathrm{Cs}^{+}$, having an ionic radius of $1.67 \AA .{ }^{24}$ This 

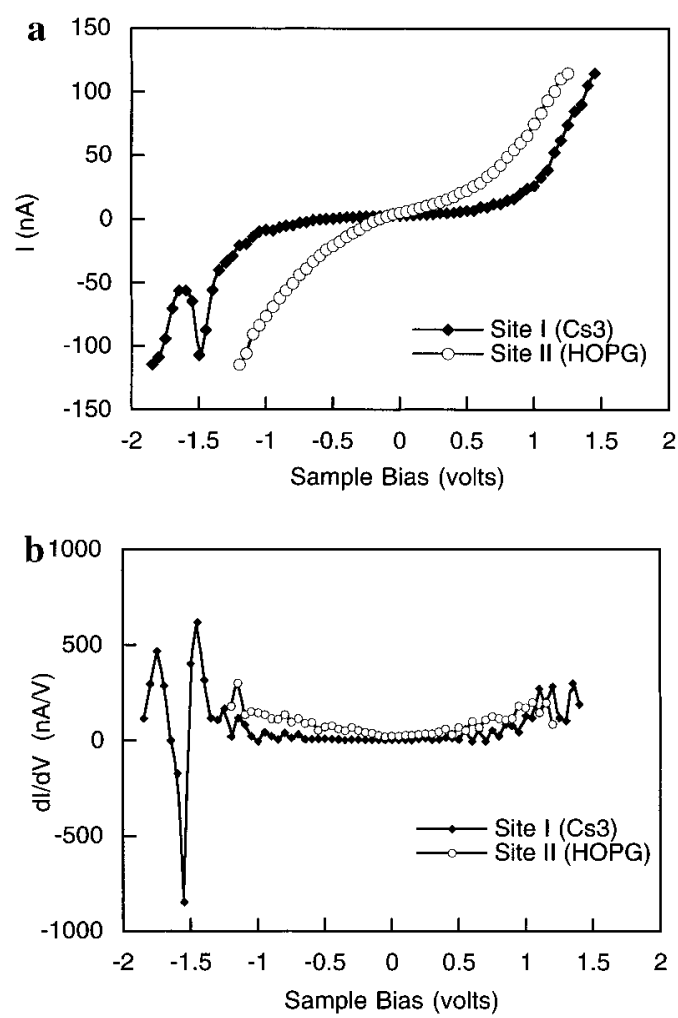

Figure 3. (a) $I-V$ spectrum and (b) $\mathrm{d} I / \mathrm{d} V$ spectrum of site I (heteropoly anion) and site II (HOPG) shown in Figure 2c.

difference in the sizes of the cations leads to differences in the lattice constants of these materials ${ }^{25}$ and likewise in the periodicities of the surface arrays formed from them. The STM images of $\mathrm{Cs}_{3} \mathrm{PMo}_{12} \mathrm{O}_{40}$ and $\mathrm{Cu}_{3 / 2} \mathrm{PMo}_{12} \mathrm{O}_{40}$ give very clear evidence for the flexible nature of the secondary structure of heteropoly acids and their salts.

Acidic protons, water of crystallization, and cations exist in the interstices between polyanions in the solid state as shown schematically in Figure 1.25 The analogous site in the STM image of the 2-D array of $\mathrm{Cs}_{3} \mathrm{PMo}_{12} \mathrm{O}_{40}$ is labeled as site III in Figure 2c. It is apparent from comparisons of the STM images in Figure 2 that, when protons were replaced with large cations such as $\mathrm{Cs}^{+}$, the lattice spacing of the ordered, 2-D array of heteropoly anions increased to accommodate the larger cations in the interstices.

Monolayer Deposition of $\mathrm{Cs}_{3} \mathrm{PMo}_{12} \mathrm{O}_{40}$. In the present system, there is no particular reason to expect strong chemical and electronic interactions between the deposited heteropoly anions and the HOPG substrate. Indeed, the formation of ordered arrays with periodicities unrelated to that of the chemically inert HOPG substrate argues against binding at specific surface sites and against strong surface-adsorbate interaction.

$I-V$ spectra of a $\mathrm{Cs}_{3} \mathrm{PMo}_{12} \mathrm{O}_{40}$ array on HOPG taken at two different positions, denoted as site I and site II in Figure 2c, are shown in Figure 3a. Site II exhibits the typical $I-V$ spectrum of freshly cleaved HOPG, and site I exhibits the characteristic $I-V$ spectrum of $\mathrm{Cs}_{3} \mathrm{PMo}_{12} \mathrm{O}_{40}$. The latter spectrum shows a negative differential resistance (NDR) feature at ca. $-1.50 \mathrm{~V} ; \mathrm{d} I / \mathrm{d} V$ is negative in this region as shown in Figure $3 \mathrm{~b}$. The difference in the $I-V$ spectra of the two sites, and the ability to resolve the tunneling spectrum of graphite at the high symmetry interstitial position, indicate that the array of $\mathrm{Cs}_{3} \mathrm{PMo}_{12} \mathrm{O}_{40}$ on HOPG is a monolayer, at least in the region of this clear STM image. The striking NDR behavior of heteropoly acids measured by STM may be closely related to the electronic properties of these materials and may serve as a fingerprint of their reactivity or redox properties.

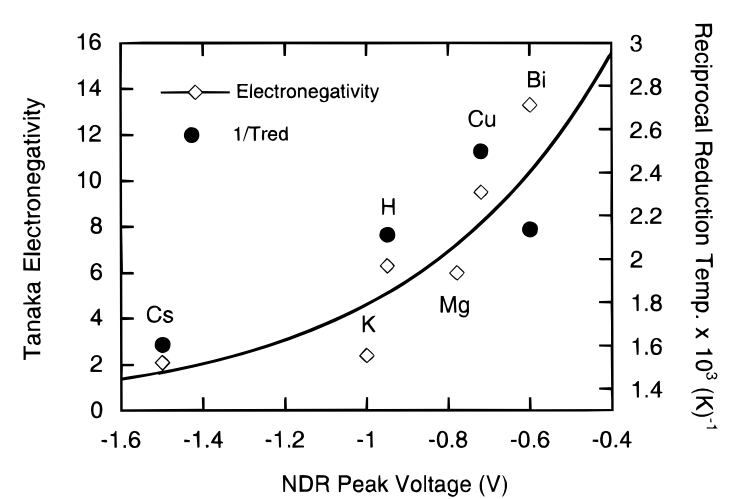

Figure 4. A correlation between NDR voltage and countercation electronegativity ${ }^{29}$ of $\left(\mathrm{M}^{n+}\right)_{3 / n}\left[\mathrm{PMo}_{12} \mathrm{O}_{40}\right]^{3-}$ and between NDR voltage and reduction temperature ${ }^{3}$ of $\left(\mathrm{M}^{n+}\right)_{3 / n}\left[\mathrm{PMo}_{12} \mathrm{O}_{40}\right]^{3-}$, where $\mathrm{M}$ represents the countercation, $\mathrm{H}, \mathrm{Mg}, \mathrm{Cu}$, etc.

Effect of Countercation on NDR. The reducibility and the reoxidizability (hence, the redox power) of 12-molybdophosphoric acid, $\mathrm{H}_{3} \mathrm{PMo}_{12} \mathrm{O}_{40}$, can be changed by the replacement of the proton with various countercations. In fact, this is the method by which heteropoly acids have been modified to have the proper activity and selectivity as catalysts in various oxidation processes. ${ }^{26}$ Simple explanations such as surface area and structural modification by the countercation have been discarded because the oxidation activity of $\mathrm{Cs}_{3} \mathrm{PMo}_{12} \mathrm{O}_{40}$, which has a relatively high surface area $\left(217 \mathrm{~m}^{2} / \mathrm{g}\right)$, is an order of magnitude lower than that of $\mathrm{BiPMo}_{12} \mathrm{O}_{40}$, which has a low surface area $\left(4.3 \mathrm{~m}^{2} / \mathrm{g}\right)$ in reactions such as the oxidations of methyl ethyl ketone ${ }^{27}$ and of butadiene. ${ }^{28}$ Also, X-ray and IR observations $^{27}$ and STM images have all shown that these heteropoly acids still maintain their characteristic Keggin structure after changing the identity of the countercations. It has been shown that the activities for oxidation of methacrolein ${ }^{3}$ and methyl ethyl ketone ${ }^{27}$ on various cation-exchanged 12molybdophosphoric acids (HPA salts) increase with increasing electronegativity of the countercation. When the reduction temperature (defined as the temperature at which the $\mathrm{H}_{2}$ consumption by the HPA salt reached 0.3 mole per mol of the pure 12-molybdophosphoric acid in TPR experiments) was employed as the index of reducibility, it became apparent ${ }^{3,27}$ that the increase in the oxidation activity was due to the increase in the reduction potential of the HPA salts with more electronegative countercations.

In the present studies, the tunneling spectra of various HPA salts were measured by STM. These results suggest a correlation of the NDR behavior in the tunneling spectra of different HPA salts not only with the electronegativity of the countercation of the HPA salt but with the reducibility or the "reduction temperature" of the salt as well. Figure 4 shows the reciprocal of the reduction temperature as measured by $\mathrm{Ai}^{3}$ and the electronegativity of the countercations, both plotted with respect to the NDR peak voltages measured for arrays of cationexchanged 12-molybdophosphates. Reduction temperature data for magnesium and potassium salts were not available. The electronegativity scale chosen was that defined by Tanaka ${ }^{29}$ which takes into account both the electron-donating and -accepting ability of the countercation. The reduction temperature of cation-exchanged 12-molybdophosphate HPAs decreases with increasing Tanaka electronegativity of the countercation. ${ }^{3}$ In other words, the reduction potential of the HPA increases with increasing electronegativity of the countercation. The applied voltage at which NDR behavior was observed in the tunneling spectrum of these HPA salts also decreased in magnitude with increasing electronegativity of the countercation, with some scatter as shown in Figure 4. These results suggest that one can correlate the reduction potential of the HPA with 


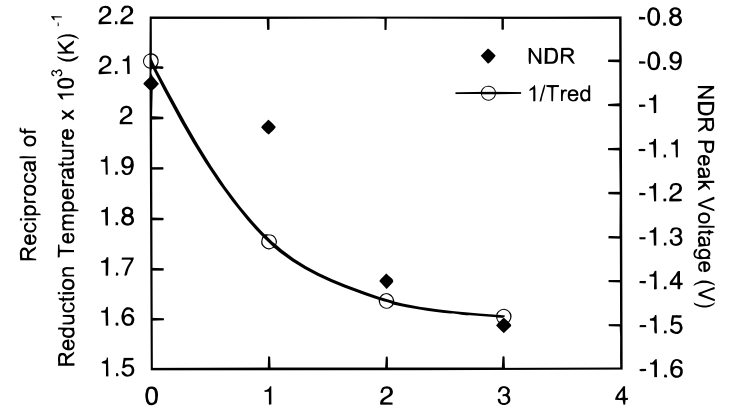

Cs content, $x$, in $\mathrm{H}_{3 \cdot x} \mathrm{Cs}_{x} \mathrm{PMo}_{12} \mathrm{O}_{40}$

Figure 5. NDR behavior and reduction temperature ${ }^{3}$ of $\mathrm{H}_{3-x} \mathrm{Cs}_{x} \mathrm{PMo}_{12} \mathrm{O}_{40}$ as a function of Cs content.

NDR peak voltages determined by tunneling spectroscopy measured with STM. The more electronegative countercationexchanged HPAs show higher reduction potentials and NDR peak voltages of smaller magnitude.

The mechanism proposed for redox catalysis by these HPAs involves electron transfer between the molybdenum framework ions and adsorbed hydrogen or oxygen. ${ }^{30}$ Any process that facilitates this electron transfer should increase the redox power of the HPA catalyst. These countercations are suggested to function as electron reservoirs, providing an easier route for electron transfer during the redox process. ${ }^{27}$ The more electronegative the countercation, the easier the electron transfer between the countercation and heteropoly anion. ${ }^{27}$ Greater ease of electron transfer appears to be associated with the occurrence of NDR behavior at less negative applied voltages in the tunneling spectra of these heteropoly acids.

NDR Behavior of $\mathrm{H}_{3-x} \mathrm{Cs}_{x} \mathrm{PMo}_{12} \mathrm{O}_{40}$ and $\mathrm{H}_{3-x} \mathrm{Cu}_{x / 2} \mathrm{P}-$ $\mathbf{M o}_{12} \mathbf{O}_{40}$. HPA catalysts based on 12-molybdophosphoric acid, $\mathrm{H}_{3} \mathrm{PMo}_{12} \mathrm{O}_{40}$, are known to perform excellently in certain mild oxidation reactions, notably in "acid-formation-type" reactions. ${ }^{3}$ One such reaction involves the commercial production of methacrylic acid by direct oxidation of methacrolein. ${ }^{31}$ It has been found that when the identity of the countercation of the heteropoly anion (12-molybdophosphate) is fixed and the extent of exchange is varied, the oxidation activity for methacrolein varies significantly in a manner that is distinctly different from the acidity of the catalyst measured by means of the adsorption of $\mathrm{NH}_{3}{ }^{28}$ The reducibilities of salts of 12-molybdophosphoric acid, $\mathrm{M}_{x / n} \mathrm{H}_{3-x} \mathrm{PMo}_{12} \mathrm{O}_{40}$ (where $\mathrm{M}$ is an $n$-valent cation), were measured by $\mathrm{Ai}$ in a closed system using $\mathrm{H}_{2} \cdot{ }^{3}$ The temperature at which $\mathrm{H}_{2}$ consumption reached $0.3 \mathrm{~mol}$ per mole of 12-molybdophosphoric acid (denoted as "the reduction temperature") was employed as the index of reducibility. The lower this reduction temperature, the higher the reduction potential (or oxidizing power) of the HPA. In the present experiments, the tunneling spectra of cesium and copper salts of 12molybdophosphoric acid were measured. All of these HPAs exhibited distinctive negative differential resistance (NDR) behavior in their respective tunneling spectra. NDR behavior was observed in all cases for these materials when electrons tunnel from the sample to the tip, i.e., at negative applied potentials. Most importantly, the applied potentials at which NDR was observed in the spatially resolved tunneling spectra for these HPAs at different levels of cation exchange could be directly correlated to the reduction temperature ${ }^{3}$ and hence to the reduction potential of each. Figure 5 shows this relationship between the NDR peak voltages measured in the current study and the reciprocal of the reduction temperature measured by $\mathrm{Ai}^{3}$ for Cs-exchanged 12-molybdophosphates, $\mathrm{H}_{3-x} \mathrm{Cs}_{x} \mathrm{PMo}_{12} \mathrm{O}_{40}$. Replacement of a proton by a cesium cation decreases the reduction potential (increases the reduction temperature) of the

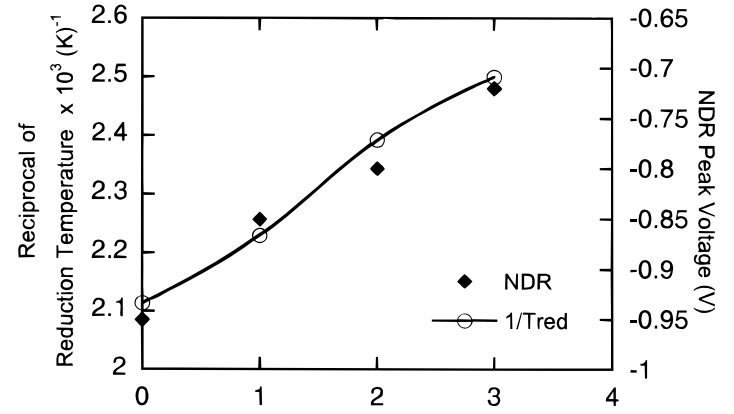

Cu content, $x$, in $\mathrm{H}_{3 \cdot x} \mathrm{Cu}_{\mathrm{x} / 2} \mathrm{PMo}_{12} \mathrm{O}_{40}$

Figure 6. NDR behavior and reduction temperature ${ }^{3}$ of $\mathrm{H}_{3-x^{-}}$ $\mathrm{Cu}_{x / 2} \mathrm{PMo}_{12} \mathrm{O}_{40}$ as a function of $\mathrm{Cu}$ content.

HPA catalyst and shifts the NDR peak voltage to larger negative values in the measured tunneling spectrum. Hence, the less reducible the catalyst, the more negative the applied potential at which NDR behavior is observed in its tunneling spectrum. However, replacement of the protons by copper has the exact opposite effects on redox properties and on the NDR behavior of the HPA catalyst. Figure 6 shows these effects for $\mathrm{Cu}$ exchanged 12-molybdophosphates, $\mathrm{H}_{3-x} \mathrm{Cu}_{x / 2} \mathrm{PMo}_{12} \mathrm{O}_{40}$. The reduction potentials of this family of HPA catalysts increase with increases in $\mathrm{Cu}$ content. We observed in the spatially resolved tunneling spectroscopy of these catalysts that the applied potential at which NDR behavior was observed decreased in magnitude with increasing copper content. Again, this indicates that the more reducible the catalyst, the less negative the NDR peak voltage in the tunneling spectrum.

These results strongly support the hypothesis that an electronic property of cation-exchanged heteropoly acids, i.e., the reduction potential of the catalyst, is closely related to their NDR behavior. It has been reported ${ }^{3,27}$ that the reduction potential of these HPAs increases with increasing $\mathrm{Cu}$ content and decreases with increasing $\mathrm{Cs}$ content. The trends demonstrated in Figures 5 and 6 must be due to the different effects that the $\mathrm{Cu}$ and $\mathrm{Cs}$ ions have on the electronic properties and reduction potential of $\mathrm{PMo}_{12} \mathrm{O}_{40}{ }^{3-}$. Previous studies ${ }^{27}$ have investigated and attempted to explain the influence of countercation properties on reduction potentials of the phosphomolybdate HPAs. Electron binding energies of molybdenum and cesium and copper cations in cesium-exchanged and copper-exchanged HPA salts were measured by XPS before and after reduction in $\mathrm{H}_{2} \cdot{ }^{27}$ In that study, it was found that reduction decreased the binding energy of the $\mathrm{Cu} 2 \mathrm{p}$ level in the $\mathrm{Cu}$ salt by $0.6 \mathrm{eV}$ but decreased that of the $3 \mathrm{~d}$ level in the $\mathrm{Cs}$ salt by only $0.1 \mathrm{eV}$, suggesting that the $\mathrm{Cu}$ ion gained more electrons than the $\mathrm{Cs}$ ion during the reduction process. ${ }^{27}$ Since the electrons supplied to the sample by reduction are presumably distributed between the heteropoly anion framework and the countercations such as copper or cesium, it has been suggested that copper, which is more electronegative than cesium, acts as a large electron reservoir to facilitate electron transfer to the molybdenum ion in the reducing environment by providing a route for electron delocalization. ${ }^{27}$

The physics of the NDR phenomenon, particularly for these HPA arrays, is not completely understood, but the trends observed can be explained in a consistent fashion. Several previous studies ${ }^{32-34}$ have demonstrated localized NDR behavior in STM and TS studies in semiconductor systems. In these examples, NDR is associated with atomic to nanometer scale defects, including boron atoms on $\mathrm{Si}(111),{ }^{32,33}$ and missing dimer defects in germanium overlayers on $\mathrm{Si}(001) .{ }^{34}$ Similar behavior in the $I-V$ characteristics of Si-doped (AlGa)As double barrier resonant-tunneling devices has been attributed to Si donor 
pairs. $^{35}$ Localized NDR behavior in these cases has been explained in terms of a double-barrier resonant-tunneling diode ${ }^{35,36}$ resonant tunneling occurs via alignment of energetically narrow electronic states within this quantum well with the Fermi levels of the substrate or tip. In the present example, the HPAs function as individual quantum wells; the energetically narrow electronic states through which resonant tunneling occurs are presumably the frontier orbitals of these molecules. Calculations of the density of states of representative Keggin ions suggest that the HOMO is largely associated with the bridging oxygen atoms in these structures; the LUMO is composed of Mo 4d and (bridging) $\mathrm{O} 2 \mathrm{p}$ orbitals and is antibonding with respect to the Mo-O bond. ${ }^{37}$ ESR measurements of reduced Keggin ions have demonstrated delocalization of electrons in these frontier orbitals over the entire cluster. ${ }^{38-40}$ That these levels, which are also expected to determine the redox properties of these compounds, ${ }^{37}$ are influenced by countercations is apparent even to the naked eye. Bulk samples of these materials are highly colored, and the color varies with cation exchange (as well as framework and heteroatom substitution). The unique aspect of the tunneling spectroscopy experiment, which detects NDR behavior arising from resonant tunneling via frontier orbitals of these HPAs, is that it does so with spatial definition at the level of the individual molecule. In effect, it permits one to probe the redox properties of reactive surfaces site-bysite across the surface. In the present work, we have distinguished the electronic properties of HPAs in 2-D arrays from those of the interstitial sites between the anions. Comparison of the NDR behavior of single-component HPA arrays demonstrates that the better the electron donor ability (the higher the Tanaka electronegativity) of the countercation, the smaller the magnitude of the potential at which NDR is observed for the HPAs in the array. It remains to be seen whether site-bysite variations of the NDR peaks can be resolved for arrays containing mixtures of HPAs with different redox properties. Such investigations are currently underway.

\section{Conclusions}

In this work, cation-exchanged 12-molybdophosphates deposited on a graphite surface were imaged, and their $I-V$ spectra were measured by scanning tunneling microscopy. Cationexchanged heteropoly acids formed two-dimensional ordered arrays on HOPG, and the periodicity of the arrays was different depending on the countercation used. This is strong evidence for the lability of the secondary structure of heteropoly acids.

We propose a correlation between NDR behavior in the tunneling spectra and reduction potential of the cation-exchanged heteropoly acids and, additionally, between NDR and Tanaka electronegativity ${ }^{29}$ of the countercation. The more electronegative cation-exchanged HPAs have higher reduction potentials and showed NDR behavior at less negative applied voltages in their tunneling spectra. The correlation between reduction potentials and NDR peak voltages is strongly reinforced by studies varying the extent of countercation substitution in $\mathrm{H}_{3-x} \mathrm{Cs}_{x} \mathrm{PMo}_{12} \mathrm{O}_{40}$ and $\mathrm{H}_{3-x} \mathrm{Cu}_{x / 2} \mathrm{PMo}_{12} \mathrm{O}_{40}$. Cesium substitution produces a monotonic increase of the reduction temperature and causes the NDR peak to shift to larger negative voltages. Copper substitution has the opposite effect on both HPA reducibility and NDR voltage in tunneling spectroscopy. Further, the spatial resolution of these tunneling spectroscopic measurements suggests that this approach might be employed to characterize redox properties site by site across a reactive surface.
Acknowledgment. Funding for this research was provided by the National Science Foundation (Grant CTS 9410965). The Topometrix 2010 STM was acquired via an equipment grant from the U.S. Department of Energy.

\section{References and Notes}

(1) Misono, M. Catal. Rev.-Sci. Eng. 1987, 29, 269.

(2) Izumi, Y.; Matsuo, K.; Urabe, K. J. Mol. Catal. 1983, 18, 299.

(3) Ai, M. Appl. Catal. 1982, 4, 245.

(4) Song, I. K.; Shin, S. K.; Lee, W. Y. J. Catal. 1993, 144, 348.

(5) Song, I. K.; Lee, J. K.; Lee, W. Y. Appl. Catal. 1994, 119, 107.

(6) Misono, M.; Okuhara, T.; Ichiki, T.; Arai, T.; Kanda, Y. J. Am. Chem. Soc. 1987, 109, 5535.

(7) Ai, M. J. Catal. 1984, 85, 324.

(8) Moffat, J. B.; Highfield, J. G. J. Catal. 1984, 88, 177.

(9) Keggin, J. F. Nature 1933, 131, 908.

(10) Watson, B. A.; Barteau, M. A.; Haggerty, L.; Lenhoff, A. M.; Weber, R. S. Langmuir 1992, 8, 1145.

(11) Loo, B. H.; Liu, Z. F.; Fujishima, A. Surf. Sci. 1990, 227, 1.

(12) Haggerty, L.; Watson, B. A.; Barteau, M. A.; Lenhoff, A. M. J. Vac. Sci. Technol. B 1991, 9, 1219

(13) Mizutani, W.; Shigeno, M.; Ono, M.; Kajimura, K. Appl. Phys. Lett. 1990, 56, 1974.

(14) Lindsay, S. M.; Sankey, O. F.; Li, Y.; Herbst, C.; Rupprecht, A. J. Phys. Chem. 1990, 94, 4655.

(15) Keita, B.; Nadjo, L. Surf. Sci. Lett. 1991, 254 , L443.

(16) Keita, B.; Chauveau, F.; Théobald, F.; Bélanger, D.; Nadjo, L. Surf. Sci. 1992, 264, 271.

(17) Ge, M.; Zhong, B.; Klemperer, W. G.; Gewirth, A. A. J. Am. Chem. Soc. 1996, 118, 5812.

(18) Song, I. K.; Kaba, M. S.; Coulston, G.; Kourtakis, K.; Barteau, M. A. Chem. Mater. 1996, 8, 2352.

(19) Song, I. K.; Kaba, M. S.; Barteau, M. A. J. Phys. Chem. 1996, $100,17528$.

(20) Kaba, M. S.; Song, I. K.; Duncan, D. C.; Hill, C. L.; Barteau, M. A. J. Am. Chem. Soc., submitted.

(21) Okuhara, T.; Nishimura, T.; Watanabe, H.; Misono, M. J. Mol. Catal. 1992, 74, 247.

(22) Tatematsu, S.; Hibi, T.; Okuhara, T.; Misono, M. Chem. Lett. 1984 865 .

(23) Okuhara, T.; Kasai, A.; Hayakawa, N.; Yoneda, Y.; Misono, M. J. Catal. 1983, 83, 121.

(24) Weast, R. C., Lide, D. R., Astle, M. J., Beyer, W. H., Eds. CRC Handbook of Chemistry and Physics; CRC Press: Boca Raton, FL, 1989; p F-187.

(25) Misono, M. New Frontiers in Catalysis, Proceedings of the 10th International Congress on Catalysis; July 1992 (Budapest, Hungary); Guczi, L., Solymosi, F., Tetenyi, P., Eds.; Elsevier: Amsterdam, 1992; p 69.

(26) Tanabe, K.; Misono, M.; Ono, Y.; Hattori, H. New Solid Acids and Bases; Elsevier: Amsterdam, 1989.

(27) Kim, H. C.; Moon, S. H.; Lee, W. Y. Chem. Lett. 1991, 447

(28) Ai, M. J. Catal. 1981, 71, 88.

(29) Tanaka, K.; Ozami, A. J. Catal. 1967, 8, 1.

(30) Misono, M.; Mizuno, N.; Katamura, K.; Kasai, A.; Konishi, Y.; Sakata, K.; Okahara, T.; Yoneda Y. Bull. Chem. Soc. Jpn. 1982, 55, 400.

(31) Shimizu, N.; Ueshima, M.; Wada, M. Shokubai 1988, 30, 555.

(32) Lyo, I.-W.; Avouris, P. Science 1989, 245, 1369.

(33) Bedrossian, P.; Chen, D. M.; Mortensen, K.; Golovchenko, J. A. Nature 1989, 342, 258.

(34) Müssig, H.-J.; Krüger, D.; Hinrich, S.; Hansson, P. O. Surf. Sci. 1994, 314, L884.

(35) Geim, A. K.; Foster, T. J.; Nogaret, A.; Mori, N.; McDonnell, P. J.; La Scala, N., Jr.; Main, P. C.; Eaves, L. Phys. Rev. B 1994, 50, 8074. (36) Maboudian, R.; Carraro, C.; Weinberg, W. H. Surf. Sci. 1993, 280, L263.

(37) Eguchi, K.; Seiyama, T.; Yamazoe, N.; Katsuki, S.; Taheta, H. J. Catal. 1988, 111, 336.

(38) Lannay, J. P.; Fournier, M.; Sanchez, C.; Livage, J.; Pope, M. T. Inorg. Nucl. Chem. Lett. 1980, 16, 257.

(39) Otake, M.; Koniyama, Y.; Otaki, T. J. Phys. Chem. 1973, 77, 2896. (40) Serwicka, E. M.; Black, J. B.; Goodenough, J. B. J. Catal. 1987, $106,23$.

JP962216M 